\title{
Thermohydrodynamic analysis of a textured sector-pad thrust bearing: effects on mechanical deformations
}

\author{
A. Charitopoulos ${ }^{1, a}$, D. Fouflias ${ }^{1}$, C.I. Papadopoulos ${ }^{1}$, L. Kaiktsis $^{1}$ And M. Fillon ${ }^{2}$ \\ 1 School of Naval Architecture and Marine Engineering, National Technical University of Athens, Zografos, Greece \\ 2 Institut Pprime, CNRS - University of Poitiers - ENSMA, Dpt GMSC, Futuroscope Chasseneuil, France
}

Received 18 September 2013, Accepted 31 May 2014

\begin{abstract}
In this paper, a computational investigation of thermohydrodynamic performance and mechanical deformations of a fixed-geometry thrust bearing with artificial surface texturing is presented. A parallel eight-pad bearing is considered; the surface of each pad is partially textured with square dimples. Here, a CFD-based thermohydrodynamic modeling approach, recently introduced by the authors, is used to calculate the performance of the bearing; the THD results are then used to quantify the deformations of the bearing mechanical parts. The bearing is modelled as a sector-shaped channel, consisting of a smooth rotating wall (thrust collar) and a partially textured stationary wall (bearing pad). The bearing performance characteristics are computed by means of numerical simulations, based on the numerical solution of the Navier-Stokes and energy equations for incompressible flow, as well as on the solution of the elasticity equations for the bearing solid parts. Here, a reference texture geometry is considered, while proper thermal and structural boundary conditions are implemented. For representative film thickness values, the effect of rotational speed and collar thickness on bearing performance is quantified, and the resulting pad and rotor deformation fields are computed. It is found that, due to oil heating, the load carrying capacity decreases with rotational speed for values higher that approximately $2000 \mathrm{rpm}$. The computed rotor deformation field is representative of a fixed support beam, characterized by substantially higher levels than those of the bearing pad. Rotor deformations increase substantially at low values of collar thickness.
\end{abstract}

Key words: Thrust bearings / thermohydrodynamic lubrication / mechanical deformations / artificial surface texturing

\section{Introduction}

Robust and efficient operation of bearings is essential in a wide range of engineering applications. Over the past decade, research by different groups worldwide has demonstrated that implementing texture patterns on a bearing stator can contribute substantially to increasing bearing load capacity, while maintaining acceptable friction levels. Papadopoulos et al. [1] have considered a generic thrust bearing geometry, and demonstrated by coupling a CFD code with an optimization tool based on genetic algorithms that appropriate texture patterns, in particular optimal rectangular grooves covering a substantial portion of the stator surface after inflow, may provide high levels of load capacity. The optimal texture geometry (groove depth and total texture length) was found to vary significantly with the bearing convergence ratio and width-to-length ratio. Similar trends on the effects of texture patterns on bearing load capacity,

${ }^{a}$ Corresponding author: chpap@central.ntua.gr accompanied by illustration of reduction in friction coefficient, were presented in the works of Cupillard et al. [2] and Dobrica et al. [3]. Further attempts to optimize textured bearings include the work of Van Ostayen et al. [4] (maximization of bearing load capacity using a PDEconstrained optimization solver) and Buscaglia et al. [5] (minimization of friction coefficient of slider bearings comprising rectangular dimples). A demonstration of the advantages of pad texturing regarding thrust bearing performance is included in Tonder [6] and Etsion et al. [7]. New concepts related to sliders capable of operating in environments other than lubricating oils, under severe loading conditions corresponding to elasto-hydrodynamic operation, have been recently analyzed, mainly in terms of parametric computational studies [8-12].

Under high loading, a revisit of common assumptions regarding bearing heat transfer (and corresponding boundary conditions implemented in simulations) may be essential. In this context, the combined experimental and theoretical investigation of Dadouche et al. [13] 


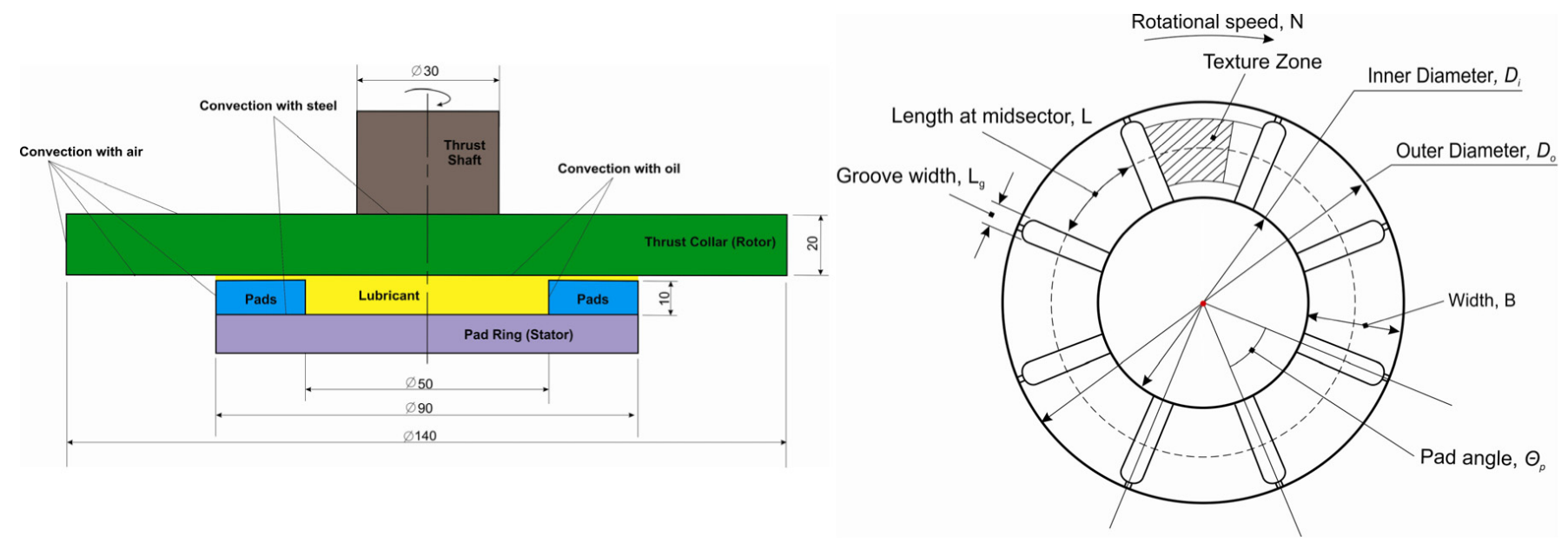

Fig. 1. Sketch of the bearing of the present study and top view of the bearing pad.

has shown that, in a highly loaded thrust bearing, over $80 \%$ of the internal heat generation due to friction is removed by the oil itself, and the rest is transferred through the solids, which is in overall agreement with previous estimates of Neal [14]. Further, the effects of solid deformation on bearing performance may also be essential. For a highly loaded fixed geometry thrust bearing, these effects were investigated in the computational study of Ahmed et al. [15]. The results of the thermoelastohydrodynamic (TEHD) study reported in [15] show that, for low values of collar thickness and high rotational speeds, a high mechanical deformation of the runner is attained, resulting in a substantial reduction of film thickness in the inner radius regime, of order $60 \%$. This results in significant differences in the values of global bearing parameters (load capacity, friction coefficient), in comparison to those corresponding to the thermohydrodynamic (THD) analysis. In another TEHD study concerning a fixed-geometry thrust bearing (Brockett et al. [16]), it was shown that performance indices are affected mainly by the pad thermal deformation, and, to a lower extent, by the pad mechanical deformation.

In summary, recent studies have shown that both thermal and mechanical deformation of a bearing stator and rotor may significantly affect its performance. The present study is a first investigation towards accounting for these effects for the case of a complex thrust bearing textured with square dimples; here, a CFD-based THD analysis is performed, and the results are utilized to quantify mechanical deformations. The present work follows the recent THD study of Papadopoulos et al. [17], extending it by considering solid deformations. The texture configuration considered here will be tested experimentally at the University of Poitiers. Thus, a goal of the present computations is to guide the experiments currently under preparation.

The paper is organized as follows: the bearing geometry is presented is Section 2, and the corresponding computational model in Section 3. Results are presented and analyzed in Section 4, while, in Section 5, the main conclusions of the present study are summarized.

\section{Thrust bearing geometry}

An overall sketch and the top view of the eight-pad fixed geometry thrust bearing modeled in the present study are shown in Figure 1.

The bearing is textured with square dimples (see Fig. 2). The inner and outer diameter of the pad are $D_{i}=50 \mathrm{~mm}$ and $D_{o}=90 \mathrm{~mm}$, respectively, and the pad thickness is $t_{p}=10 \mathrm{~mm}$. The lubrication oil (ISO VG46) is fed at the bearing inner diameter, and reaches the lubrication region via eight radial grooves. The width and depth of each groove are $L_{g}=3 \mathrm{~mm}$ and $h_{g}=4 \mathrm{~mm}$, respectively.

The textured area begins at the pad inflow, extending up to an angle of $29^{\circ}$; it can be divided into square texture cells, of side $a=1 \mathrm{~mm}$. Each cell includes a square dimple, of side $0.75 \mathrm{~mm}$ and depth of $h_{d}=20 \mu \mathrm{m}$. In the radial direction, the texture pattern is symmetric with respect to the pad mid-sector, and the texture width is $15 \mathrm{~mm}$. The bearing rotor is characterized by an outer diameter $D_{r}=140 \mathrm{~mm}$ and a thickness $t_{r}=20 \mathrm{~mm}$; its surface is planar and smooth.

\section{Computational model}

The conservation equations, solved with the CFD code ANSYS CFX for steady incompressible flow with zero gravitational and external body forces, are:

Mass conservation equation:

$$
\nabla \cdot \mathbf{V}=0
$$

Momentum equations:

$$
\rho(\mathbf{V} \cdot \nabla) \mathbf{V}=-\nabla p+\nabla \cdot(\mu \nabla \mathbf{V})
$$


Thrust Collar (Rotor)

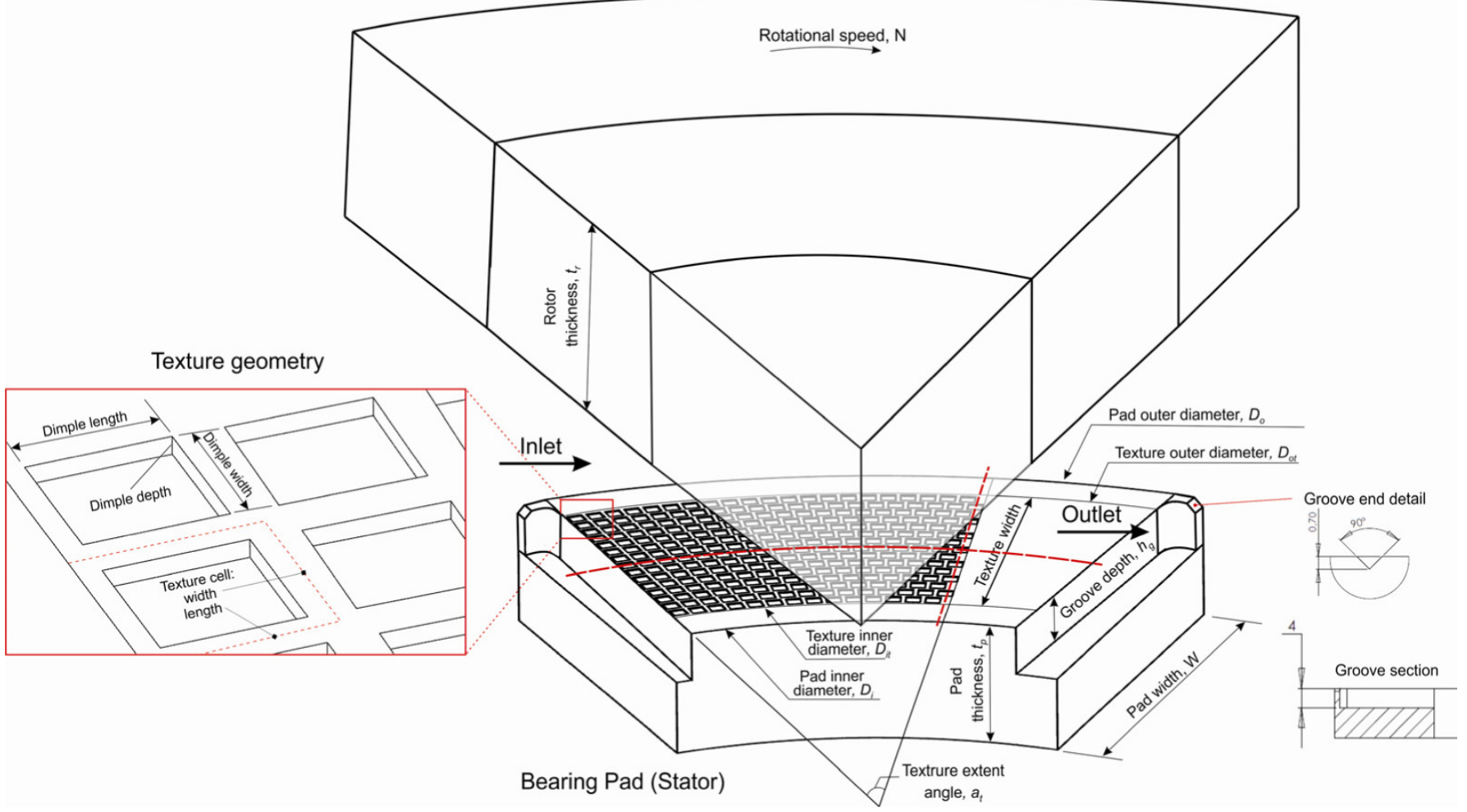

Fig. 2. Geometry of computational model.

Energy equation, fluid domain:

$$
\rho c_{p} \mathbf{V} \cdot \nabla T=\nabla \cdot\left(\lambda_{f} \nabla T\right)-\tau: \nabla \mathbf{V}
$$

Energy equation, solid domains:

$$
\nabla \cdot\left(\lambda_{s} \nabla T\right)=0
$$

where $\mathbf{V}$ is the velocity vector $(\mathrm{m} / \mathrm{s}), p$ the static pressure $(\mathrm{Pa}), T$ the temperature $(\mathrm{K}), \tau$ the viscous stress tensor, $\rho$ the oil density $\left(\mathrm{kg} / \mathrm{m}^{3}\right), \mu$ the oil dynamic viscosity $(\mathrm{kg} / \mathrm{m} . \mathrm{s}), c_{p}$ the oil specific heat capacity $(\mathrm{J} / \mathrm{kg} . \mathrm{K})$, $\lambda_{f}$ the oil thermal conductivity $(\mathrm{W} / \mathrm{m} . \mathrm{K}), \lambda_{s p}$ the pad thermal conductivity $(\mathrm{W} / \mathrm{m} . \mathrm{K})$ and $\lambda_{s r}$ the rotor thermal conductivity $(\mathrm{W} / \mathrm{m} \cdot \mathrm{K})$.

The set of equations (1)-(4) is solved by utilizing the ANSYS CFX 14.5 CFD code, in a coupled manner. Here, a second-order accurate spatial discretization is implemented, utilizing an unstructured mesh comprising hexahedral finite volumes.

The pad and the rotor undergo elastic deformation due the exerted pressure distribution and the thermal expansion. The total solid strain can be computed as:

$$
\varepsilon=\varepsilon^{\mathrm{el}}+\varepsilon^{\mathrm{th}}
$$

where $\varepsilon$ is total strain vector $=\left[\begin{array}{lllll}\varepsilon_{x} & \varepsilon_{y} & \varepsilon_{z} & \varepsilon_{x y} & \varepsilon_{y z} \varepsilon_{x z}\end{array}\right]^{T}$ and $\varepsilon^{\mathrm{el}}, \varepsilon^{\mathrm{th}}$ are the elastic and thermal strain vectors, respectively.
The elastic strain, $\varepsilon^{\mathbf{e l}}$, of each solid part can be computed from the solution of the elasticity equation:

$$
\sigma^{\mathrm{el}}=\mathbf{D} \varepsilon^{\mathrm{el}}
$$

where $\sigma^{\text {el }}$ is the elastic stress vector $\left[\begin{array}{lllll}\sigma_{x} & \sigma_{y} & \sigma_{z} & \sigma_{x y}\end{array}\right.$ $\left.\begin{array}{ll}\sigma_{y z} & \sigma_{x z}\end{array}\right]^{T}$ and $\mathbf{D}$ the stiffness matrix of the solid, given below.

$\mathbf{D}^{-1}=\left[\begin{array}{cccccc}1 / E_{x} & -\nu_{x y} / E_{x}-\nu_{x z} / E_{x} & 0 & 0 & 0 \\ -\nu_{y x} / E_{y} 1 / E_{y} & -\nu_{y z} / E_{y} & 0 & 0 & 0 \\ -v_{z x} / E_{z}-\nu_{z y} / E_{z} & 1 / E_{z} & 0 & 0 & 0 \\ 0 & 0 & 0 & 1 / G_{x y} & 0 & 0 \\ 0 & 0 & 0 & 0 & 1 / G_{y z} & 0 \\ 0 & 0 & 0 & 0 & 0 & 1 / G_{x z}\end{array}\right]$

Here, $E_{i}(i=x, y, z)$ is the Young's modulus of elasticity in the $i$ th direction, $\nu_{i j}$ is the Poisson ratio for orthotropic materials, and $G_{i j}$ is the shear modulus in the ij plane.

The solid thermal strain, $\varepsilon^{\text {th }}$, can be computed from the following relation:

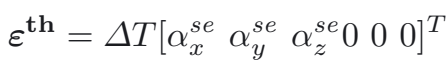

where $\varepsilon^{\text {th }}$ is the thermal strain vector, $\Delta T=T-T_{\text {ref }}$ ( $T$ is the local and $T_{\text {ref }}$ is the reference, strain-free temperature), and $\alpha_{i}^{s e}, i=x, y, z$, are the coefficients of thermal expansion in the $i$ th direction. 
Table 1. Pad and rotor convection coefficients and reference far-field temperatures. The locations are identified in the sketch of Figure 1.

\begin{tabular}{lcc}
\hline Location & $a_{\text {conv }}\left(\mathrm{W} / \mathrm{m}^{2} \cdot \mathrm{K}\right)$ & $T_{a m b}\left({ }^{\circ} \mathrm{C}\right)$ \\
\hline $\begin{array}{l}\text { Rotor-air boundary } \\
\text { (assumed convection with air) }\end{array}$ & 25 & 20 \\
$\begin{array}{l}\text { Rotor top inner surface (shaft location) } \\
\text { (assumed equivalent convection with steel) }\end{array}$ & 1000 & 20 \\
$\begin{array}{l}\text { Rotor bottom inner surface } \\
\text { (assumed convection with lubricating oil) }\end{array}$ & 200 & 40 \\
$\begin{array}{l}\text { Pad inner surface } \\
\text { (assumed convection with lubricating oil) }\end{array}$ & 200 & 40 \\
$\begin{array}{l}\text { Pad outer surface } \\
\text { (assumed convection with air) }\end{array}$ & 25 & 40 \\
$\begin{array}{l}\text { Pad bottom } \\
\text { (assumed equivalent convection with steel) }\end{array}$ & 1000 & 40 \\
\hline
\end{tabular}

In the present work, the values of thermophysical properties utilized are given below:

Lubricant:

$$
c_{p}=2000 \mathrm{~J} / \mathrm{kg} . \mathrm{K}, \lambda_{f}=0.13 \mathrm{~W} / \mathrm{m} . \mathrm{K} .
$$

Solids (isotropic):

$c_{p}=434 \mathrm{~J} / \mathrm{Kg} \cdot \mathrm{K}$ and $\lambda_{s p}=50 \mathrm{~W} / \mathrm{m} \cdot \mathrm{K} \quad \lambda_{s r}=$ $60.5 \mathrm{~W} / \mathrm{m} . \mathrm{K}, \alpha_{\text {pad }}=18 \times 10^{-6} \mathrm{~K}^{-1}, \alpha_{\text {rotor }}=11.5 \times$ $10^{-6} \mathrm{~K}^{-1} E_{s p}=1.2 \times 10^{11} \mathrm{~Pa}, E_{s r}=2.1 \times 10^{11} \mathrm{~Pa}$, $\nu_{s p}=0.33, \nu_{s r}=0.3$.

The present study focuses on an identification of the elastic deformation due to the pressure field. Thus, a value of $\alpha^{s e}=0$ is set for all thermal expansion coefficients, i.e. thermal deformation is not taken into account. Extensions of the present study, also accounting for thermal deformation, will be considered in the near future.

The density of the lubrication oil utilized (ISO VG 46) is $870 \mathrm{~kg} / \mathrm{m}^{3}$, while a temperature dependent viscosity is considered, according to the McCoull and Walther relation [18]:

$$
\log \log (\nu+a)=b-n \log (T)
$$

where, $\nu$ is the kinematic viscosity (cSt), and $a=0.6$, $b=9.02865$ and $n=3.52681$.

The flow dynamics depends (a) on the Reynolds number, Re, which is defined at the thrust bearing mid-sector, in terms of the rotor speed, $U=\omega R_{m}$, and the minimum film thickness $h_{\text {min }}$ ( $\omega$ is the rotor angular velocity and $R_{m}$ the pad mid-sector radius), and (b) on the lubricant Prandtl number, at a representative temperature. In the present study, for a representative rotational speed of $4000 \mathrm{rpm}(U=14.65 \mathrm{~m} / \mathrm{s})$, a minimum film thickness value of $15 \mu \mathrm{m}$ and an average lubricant temperature of $70^{\circ} \mathrm{C}, \mathrm{Re}=13.7$. The computed thrust load is $2934 \mathrm{~N}$.

The 3-D mesh generated for the fluid domain contains approximately $2 \times 10^{6}$ hexahedral cells (finite volumes). In each pad dimple, the fluid volume mesh typically has 10 cell layers in the axial direction, $8 \times 8$ cells on a rectangular cross-section, and 8 cell layers in the statorrotor clearance. Hexahedral finite volume cells are utilized to solve for heat conduction in the solid domain, in particular approximately $10^{6}$ cells in the rotor domain and $1.5 \times 10^{6}$ cells in the pad domain. This discretization for heat conduction in the solid corresponds to a discretization of linear finite elements, utilized to solve the elasticity problem by means of ANSYS MAPDL.

No-slip conditions are implemented for the fluid velocity at the pad and rotor inner walls. The inner surface of the fluid domain is considered as an inlet boundary, with a pressure value of $1.5 \times 10^{5} \mathrm{~Pa}$ above atmospheric and a constant oil temperature of $40{ }^{\circ} \mathrm{C}$. The outer surface of the fluid domain is considered an outlet boundary, with atmospheric pressure, and a Neumann boundary condition for temperature. Regarding the groove symmetry planes (inflow and outflow boundaries for the present problem setup), rotational periodicity has been considered, both for the velocity and temperature fields. Regarding thermal boundary conditions, the rotor is assumed stationary (frozen); therefore a constant thermal loading of the rotor is computed. At the fluid-pad and fluid-rotor interfaces, continuity of temperature and heat flux is considered. At the leading/trailing edges of the rotor and the pad, conditions of rotational periodicity are applied for temperature. At the remaining external surfaces of the rotor and the pad, appropriate combinations of convection coefficient, $a_{\mathrm{conv}}$, and ambient temperature, $T_{\mathrm{amb}}$, are prescribed, following the work in [17]; they are presented in Table 1.

Regarding elasticity boundary conditions, the pad bottom is assumed fixed (zero displacements/rotations), and the rotor is assumed clamped up to a radius of $25 \mathrm{~mm}$ (pad inner radius). The fluid-pad and fluid-rotor interfaces are considered as coupling walls. A one-way fluidstructure interaction (FSI) technique has been applied to impose computed pressure on the solid surfaces, as boundary condition for solving the solid elasticity problems utilizing ANSYS MAPDL. Future extensions of the present study will consider a two-way coupling, i.e. utilize the deformed geometry to solve for the flow and heat transfer problem. The solution of the problem based on two-way coupling should terminate when the computed fields hardly change from one full iteration (solution of the flow - heat transfer and elasticity problem) to a subsequent one. 

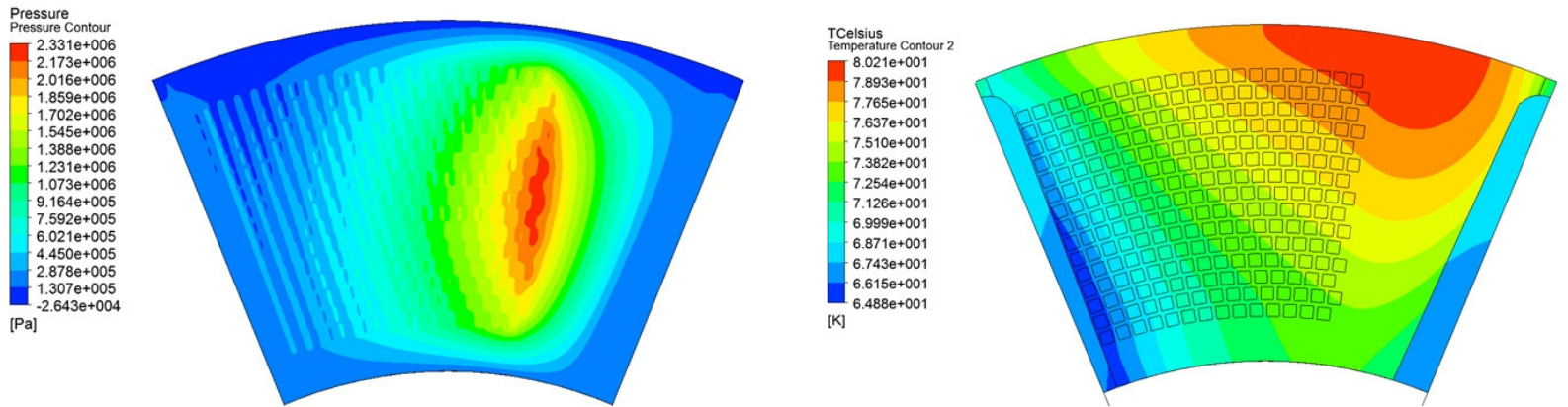

(a)
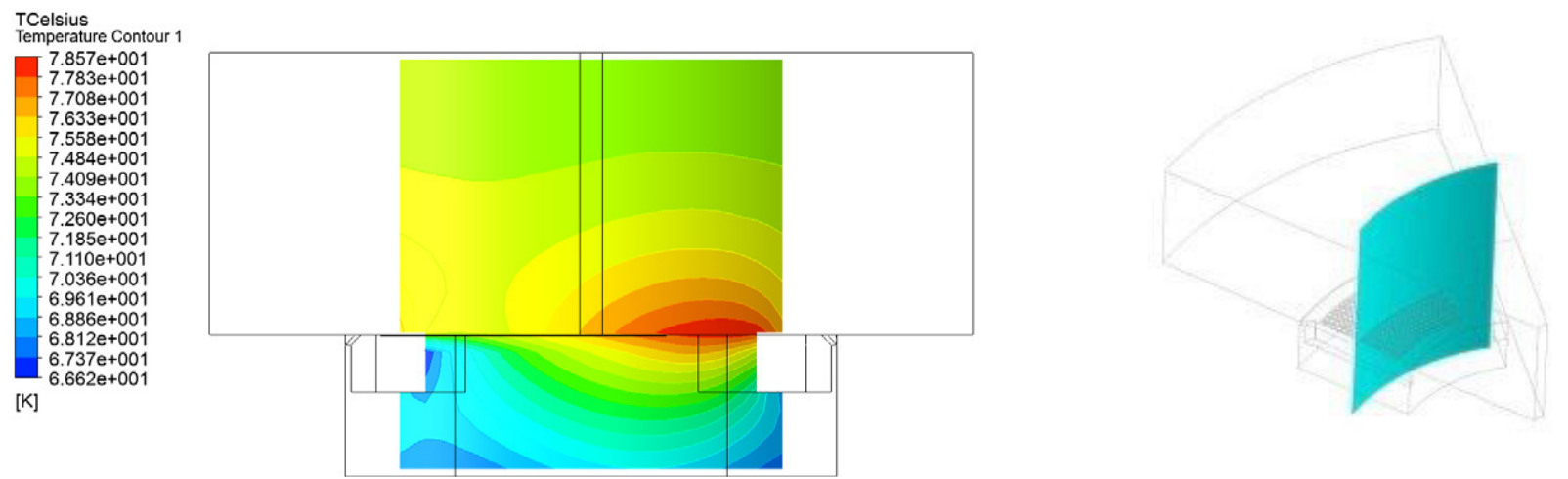

(b)

Fig. 3. Reference case $\left(N=4000 \mathrm{rpm}, h_{\min }=15 \mu \mathrm{m}\right.$, resulting in a load $\left.W=2934 \mathrm{~N}\right)$ : (a) Computed pressure distribution at the fluid-rotor interface and temperature distribution at the pad surface. (b) Temperature distribution at the pad and the collar, at a vertical cross section at the mean pad radius.

For the given problem setup, grid independence studies have considered coarser grids than the high resolution one described above. The results have demonstrated differences in load capacity and computed temperatures of the order of $1 \%$.

\section{Results}

First, bearing operation for a reference case is considered. The parameters corresponding to the reference case are $N=4000 \mathrm{rpm}$ and $h_{\min }=15 \mu \mathrm{m}$, yielding a total bearing load $W=2934 \mathrm{~N}$. The pressure distribution at the rotor-pad interface and the temperature distribution at the pad surface are presented in Figure 3a. Further, in Figure $3 \mathrm{~b}$, temperature distribution at the pad and the rotor is presented at a vertical cross section corresponding to the pad mean radius. Figure 3 a demonstrates a gradual pressure buildup along the main flow direction, reaching a maximum at the texture rear end. Regarding the temperature distribution, a maximum is identified at the outer region of the bearing, close to the outflow, and its location should be attributed to the combined effect of oil heating due to viscous dissipation and the action of centrifugal forces. The resulting elastic displacements of the collar and the pad are presented in Figure 4. A close similarity is found between the upper pad surface deformation field and the exerted pressure. The computed deformation field of the rotor is representative of a beam with fixed support, exhibiting large displacement values at large radii.

Further, the effects of bearing speed on bearing performance have been investigated, for different values of minimum film thickness, varying from $5 \mu \mathrm{m}$ to $20 \mu \mathrm{m}$. Figures $5 \mathrm{a}-5 \mathrm{~d}$ present the computed variation of load capacity and maximum fluid temperature versus rotational speed, and the corresponding variation of maximum rotor/pad displacement. Load capacity is found to increase at low rotational speeds, reaching a maximum at speeds around $2000 \mathrm{rpm}$. The subsequent decrease, a marked difference from the continuous increase of isothermal flow (see [17]), is caused by the decreased levels of oil viscosity due to heating (see continuous temperature rise in the same figure). A substantial increase in load capacity (and maximum fluid temperature) is verified at decreasing values of minimum film thickness.

Figure 5 demonstrates that the maximum displacements of the collar and the pad follow the trend of load capacity, also exhibiting a maximum value at rotational speeds of approximately $2000 \mathrm{rpm}$. In all cases, the maximum rotor displacement is substantially higher than that of the pad, which should be attributed to the corresponding difference in structural boundary conditions and effective stiffness.

Next, the effect of rotor thickness on the performance characteristics of the bearing is quantified. Figures $6 \mathrm{a}^{-}$ $6 \mathrm{f}$ present the computed variation of load capacity and 


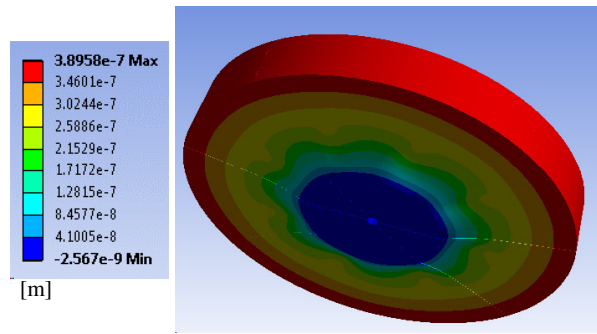

(a)

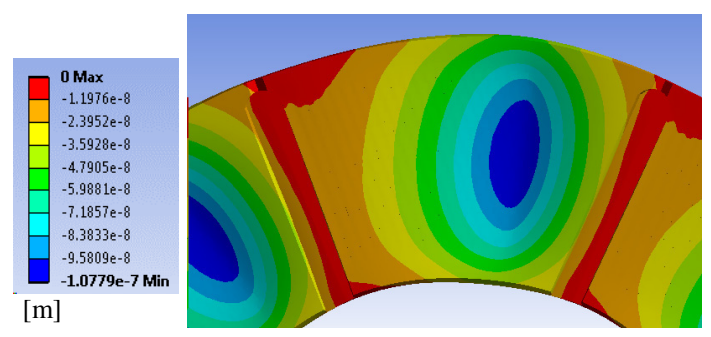

(b)

Fig. 4. Reference case $\left(N=4000 \mathrm{rpm}, h_{\min }=15 \mu \mathrm{m}\right.$, resulting in a load $\left.W=2934 \mathrm{~N}\right)$ : plots of elastic displacement at the collar and the pad domains.
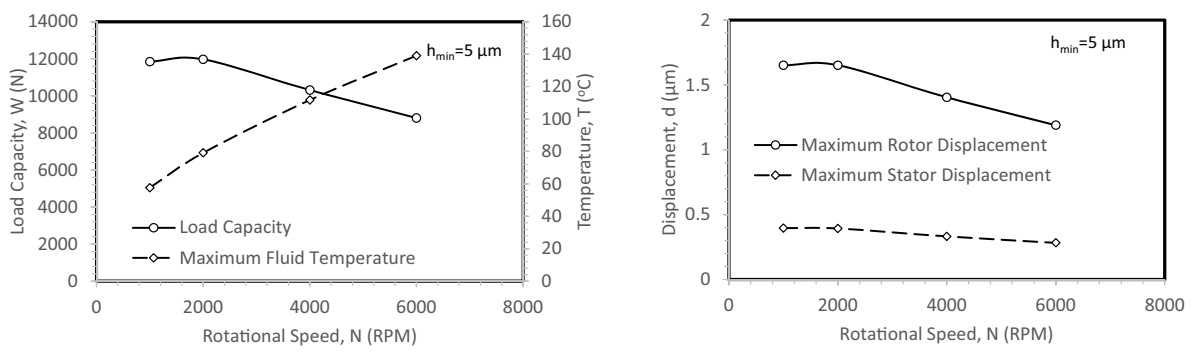

(a)
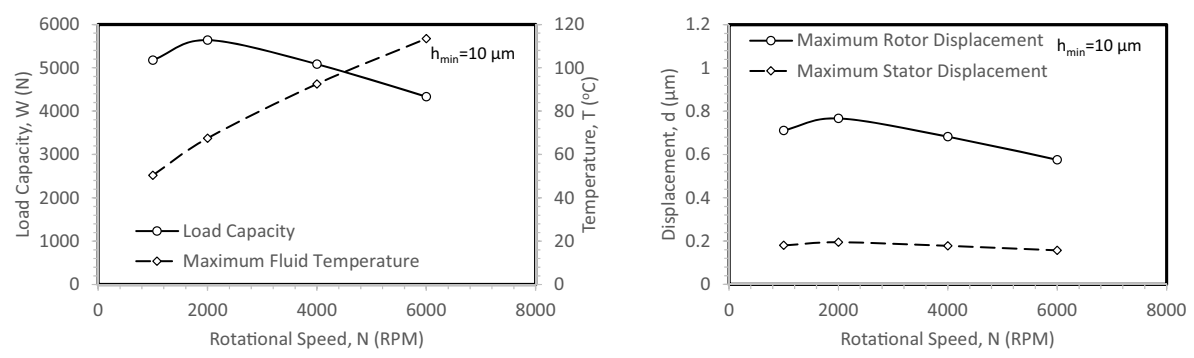

(b)
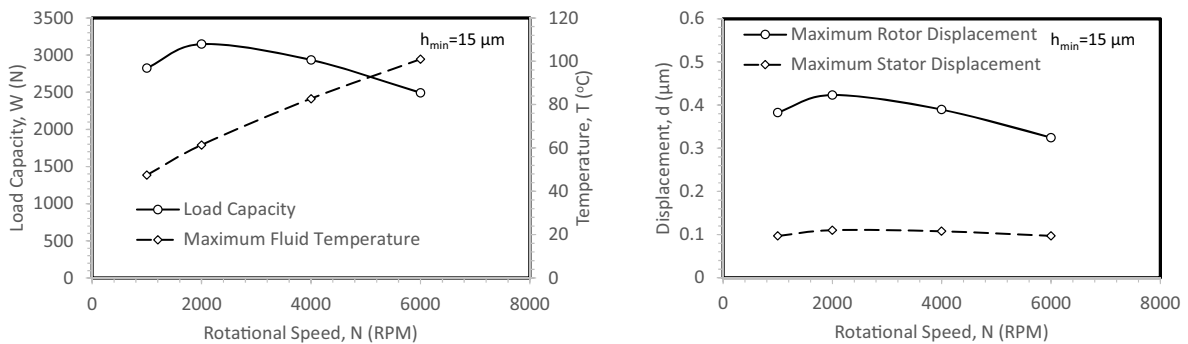

(c)
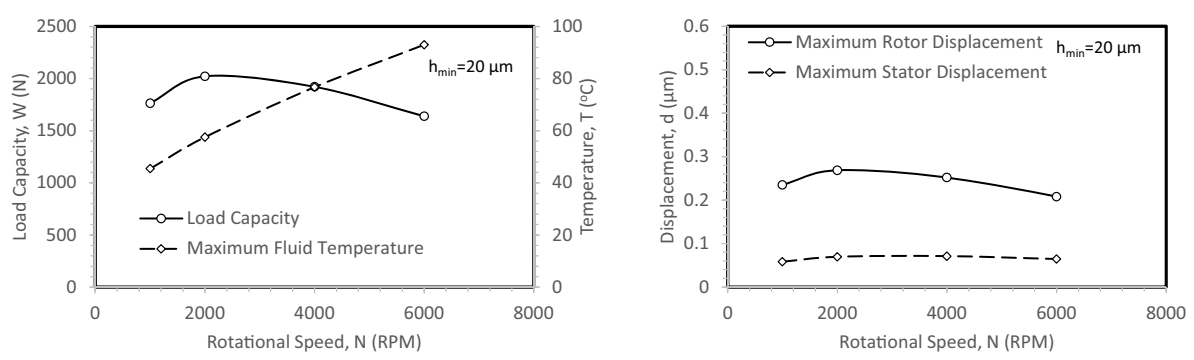

(d)

Fig. 5. Load capacity, maximum fluid temperature and maximum rotor/pad displacement versus rotational speed, for four different values of minimum film thickness. 


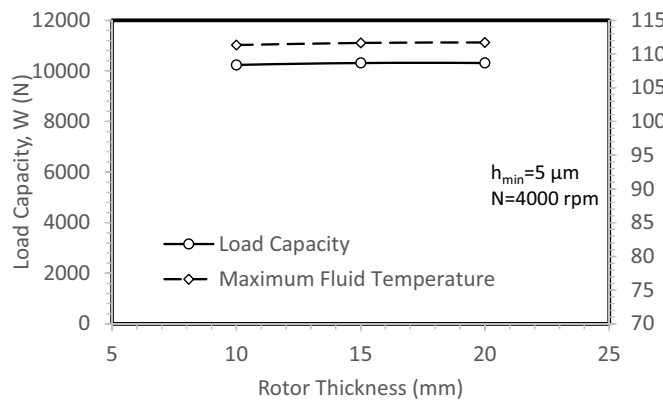

(a)

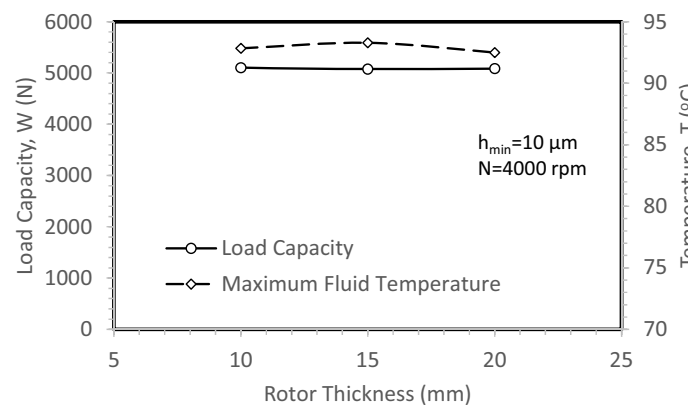

(c)

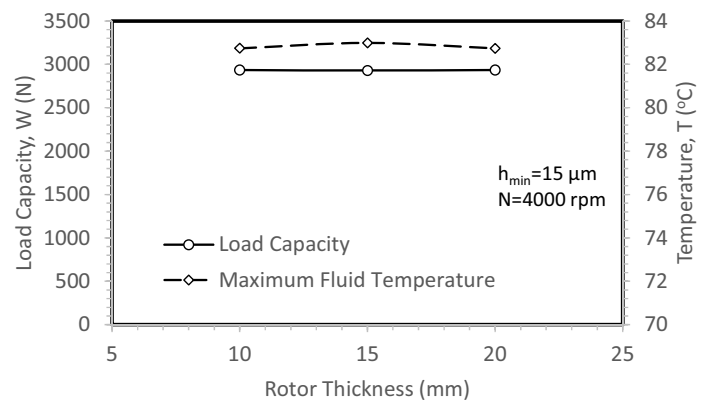

(e)

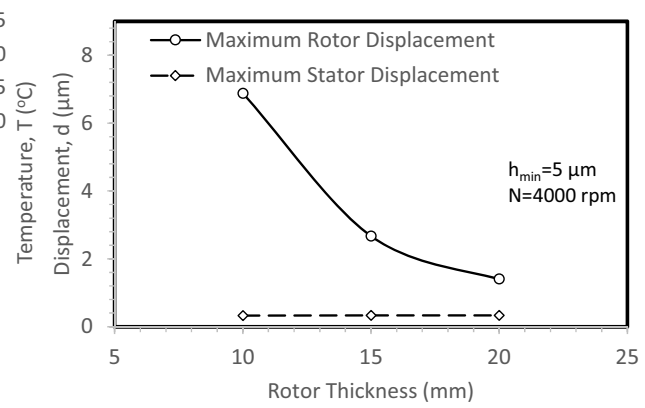

(b)

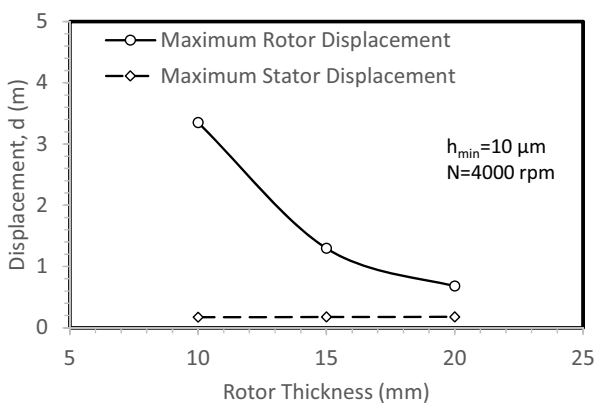

(d)

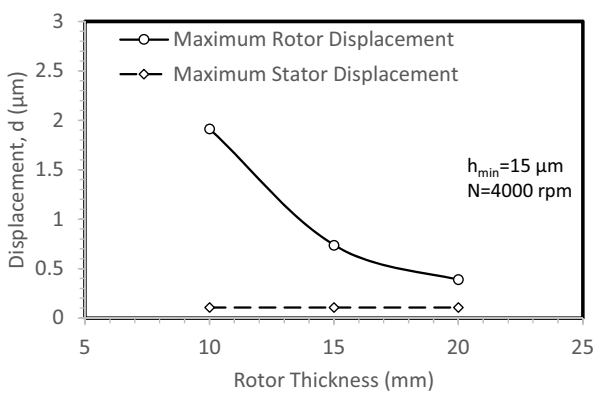

(f)

Fig. 6. Load capacity, maximum fluid temperature and maximum rotor/pad displacement versus rotor thickness, for different values of minimum film thickness.

maximum fluid temperature, and the corresponding variation of maximum rotor/pad displacement, as a function of rotor thickness, for three different values of minimum film thickness; a negligible effect on load capacity, maximum fluid temperature and pad displacement is verified. On the other hand, Figures 6b, 6d and 6f demonstrate an increase of rotor displacement with decreasing rotor thickness, qualitatively at a quadratic rate. This increase becomes very pronounced at low values of minimum film thickness.

Figure 7 presents the effect of minimum film thickness on the computed pressure distribution; here, operation at $N=4000 \mathrm{rpm}$ for a rotor thickness of $15 \mathrm{~mm}$ is considered. A pressure increase is verified for the dimpled (textured) region. Pressure levels decrease at increasing minimum film thickness. In Figure 8, the corresponding profiles of the rotor and pad displacement along the bearing mid-sector and the radial direction, the latter in the texture rear end region, are presented. Figure 8 demonstrates that, in the circumferential direction, both the rotor and pad exhibit maximum deformation at the texture rear end, i.e. in the region of maximum pressure. The same holds for the distribution along the radial direction for the bearing pad. On the other hand, due to the different structural boundary conditions, the rotor deformation in the radial direction increases monotonically at increasing radius.

\section{Conclusions}

In the present work, a computational study of thermohydrodynamic performance and mechanical deformation of a complex geometry textured thrust bearing has been presented. The bearing stator is partially textured with square dimples. In particular, a CFD-based THD analysis has been performed, along with a one-way fluid-structure interaction (FSI) coupling, yielding the displacement field 


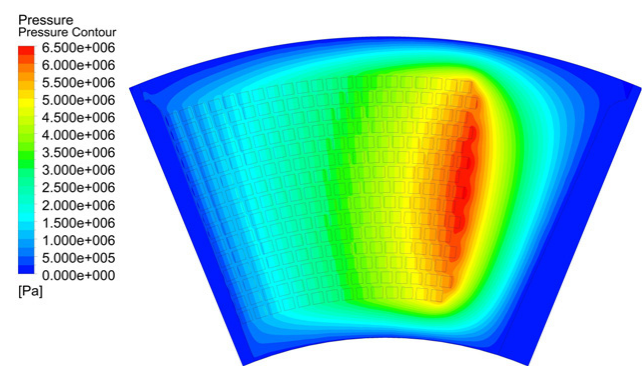

(a)

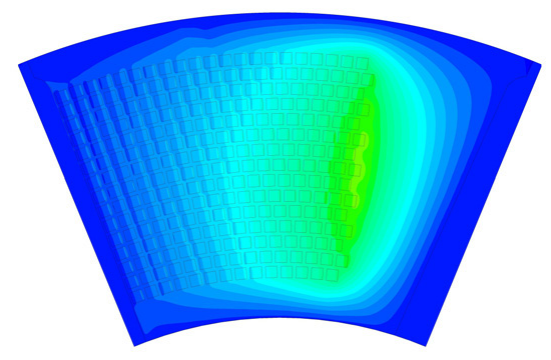

(b)

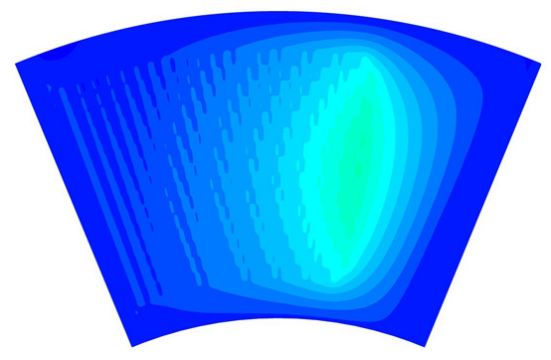

(c)

Fig. 7. Rotor thickness of $15 \mathrm{~mm}, N=4000 \mathrm{rpm}$ : Computed pressure distribution at the fluid-rotor interface, for minimum film thickness value of (a) $5 \mu \mathrm{m}$, (b) $10 \mu \mathrm{m}$, and (c) $15 \mu \mathrm{m}$.

\section{Circumferential distribution}
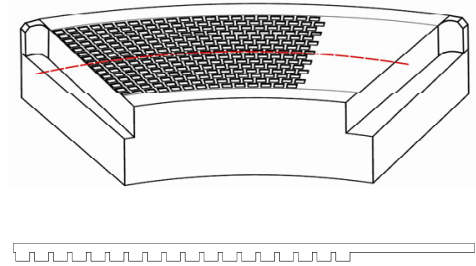

\section{Radial distribution}

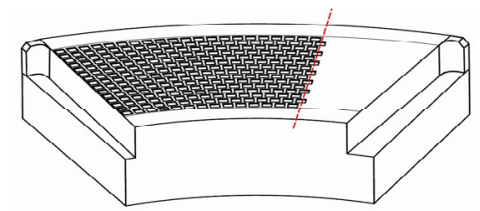

பேபேபேபே

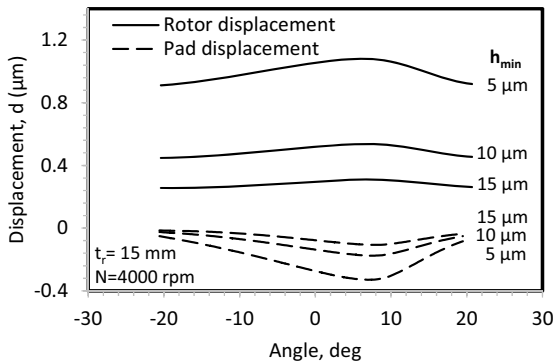

(a)

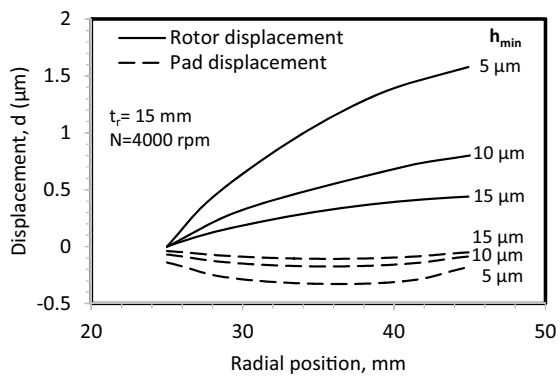

(b)

Fig. 8. Profiles of rotor/pad displacement along (a) the circumferential, and (b) the radial direction, for different values of minimum film thickness. The corresponding locations are depicted in the left column sketches.

of the solid parts (rotor collar, bearing pad). The main conclusions of this work can be summarized as follows:

- The effect of oil heating on bearing performance has been confirmed to be substantial. In particular, for constant film thickness, a decrease in load capacity with bearing rotational speed is already present at values of $\mathrm{N}$ close to $2000 \mathrm{rpm}$.

- The variation of collar and pad deformations with bearing rotational speed follows the trend of load capacity. In the fluid-pad interface region, the pad deformation bears a pattern similar to the exerted pressure distribution. The rotor deformation field is representative of a beam with fixed support. The maximum rotor deformation is substantially higher than that of the pad, and is a decreasing function of rotor thickness.
The present development yields a basis for detailed TEHD lubrication studies characterized by two-way FSI coupling in complex geometry thrust bearings.

Acknowledgements. The authors would like to acknowledge the financial support by the Greek Secretariat for Research and Technology through the TRIBO-MARINE project, grant Nr. 2595.

\section{References}

[1] C.I Papadopoulos, E.E. Efstathiou, P.G. Nikolakopoulos, L. Kaiktsis, Geometry optimization of textured 3-D micro- thrust bearings, ASME J. Tribology 133 (2011) 041702

[2] S. Cupillard, M. Cervantes, S. Glavatskih, Pressure buildup mechanism in a textured inlet of a hydrodynamic contact, J. Tribology 130 (2008) 21701 
[3] M. Dobrica, M. Fillon, M. Pascovici, Optimizing surface texture for hydrodynamic lubricated contacts using a mass-converging numerical approach, Proc. Institut. Mech. Eng. Part J: J. Eng. Tribology 224 (2010) 737-750

[4] R. Van Ostayen, A. Van Beek, R. Munnig-Schmidt, Film height optimization of hydrodynamic slider bearings. In Proceedings of the ASME/STLE International Joint Tribology Conference, IJTC 2007 PART A, 2007, pp. 237-239

[5] G. Buscaglia, R. Ausas, M. Jai, Optimization tools in the analysis of micro-textured lubricated devices, Inv. Prob. Sci. Eng. 14 (2006) 365-378

[6] K. Tonder, Effects of skew unidirectional striated roughness on hydrodynamic lubrication. Wear 115 (1987) 19-30

[7] I. Etsion, G. Halperin, V. Brizmer, Y. Kligerman, Experimental investigation of laser surface textured parallel thrust bearings, Tribology Lett. 17 (2004) 295-300

[8] R. Sharma, R. Pandey, Experimental studies of pressure distributions in finite slider bearing with single continuous surface profiles on the pads, Tribology Int. 42 (2009) 1040-1045

[9] L. Stephens, R. Siripuram, M. Hayden, B. McCrtt, Deterministic micro asperities on bearings and seals using a modified LIGA process, J. Eng. Gas Turbines Power 126 (2004) 147-154

[10] K. Thomsen, P. Klit, Analysis of a thrust bearing with flexible pads and flexible supports, Proceedings, BALTTRIB 2007 International Scientific Conference, 2007, pp. $174-180$

[11] X. Wang, J. Zhu, J. Li, W. Chen, L. Cai, Numerical analysis of elasto-hydrodynamically lubricated point contacts with three dimensional laser micro-texturing asperity, Int. J. Nonlinear Sci. Numer. Simul. 8 (2007) 553-559

[12] R. Rahmani, A. Shirvani, H. Shirvani, Optimization of partially textured parallel thrust bearings with square-shaped micro-dimples, Tribology Trans. 50 (2007) 401-406

[13] A. Dadouche, M. Fillon, W. Dmochowski, Performance of a hydrodynamic fixed geometry thrust bearing: Comparison between experimental data and numerical results, Tribology Trans. 49 (2006) 419-426

[14] P.B. Neal, Heat transfer in pad thrust bearings, Proc. Institut. Mech. Eng. 196 (1982) 216-28

[15] S. Ahmed, M. Fillon, P. Maspeyrot, Influence of pad and runner mechanical deformations on the performance of a hydrodynamic fixed geometry thrust bearing, Proc. IMech E Part J: J. Eng. Tribology 224 (2009) 305-315

[16] T.S. Brockett, L.E. Barrett, P.E. Allaire, Thermoelastohydrodynamic analysis of fixed geometry thrust bearings including runner deformation, Tribology Trans. 39 (1996) 555-562

[17] C.I. Papadopoulos, Y. Henry, J. Bouyer, L. Kaiktsis, M. Fillon, Sector-pad Thrust Bearings with Rectangular Dimples: Comparison between Experiments and CFD Thermohydrodynamic Simulations, Proceedings of the 2013 World Tribology Congress, September 8-13, 2013, Turin, Italy

[18] J. Frene, D. Nicolas, B. Degueurce, D. Berthe, M. Godet, Hydrodynamic lubrication: Bearings and thrust bearings. Elsevier, Amsterdam, 1997

[19] F. Incopera, D. De Witt, Fundamentals of heat and mass transfer, 6th edition, John Wiley \& Sons, 2006 